Subscriber access provided by Caltech Library

\title{
Article
}

\section{Cp* Non-innocence Leads to a Remarkably Weak C-H Bond via Metallocene Protonation}

\author{
Matthew J. Chalkley, Paul H. Oyala, and Jonas C. Peters
}

J. Am. Chem. Soc., Just Accepted Manuscript • DOI: 10.1021/jacs.9b00193 • Publication Date (Web): 21 Feb 2019

Downloaded from http://pubs.acs.org on February 21, 2019

\section{Just Accepted}

"Just Accepted" manuscripts have been peer-reviewed and accepted for publication. They are posted online prior to technical editing, formatting for publication and author proofing. The American Chemical Society provides "Just Accepted" as a service to the research community to expedite the dissemination of scientific material as soon as possible after acceptance. "Just Accepted" manuscripts appear in full in PDF format accompanied by an HTML abstract. "Just Accepted" manuscripts have been fully peer reviewed, but should not be considered the official version of record. They are citable by the Digital Object Identifier (DOI®). "Just Accepted" is an optional service offered to authors. Therefore, the "Just Accepted" Web site may not include all articles that will be published in the journal. After a manuscript is technically edited and formatted, it will be removed from the "Just Accepted" Web site and published as an ASAP article. Note that technical editing may introduce minor changes to the manuscript text and/or graphics which could affect content, and all legal disclaimers and ethical guidelines that apply to the journal pertain. ACS cannot be held responsible for errors or consequences arising from the use of information contained in these "Just Accepted" manuscripts. 


\section{INTRODUCTION}

Metallocenes such as ferrocene, chromocene, and cobaltocene have enjoyed a privileged role in the development of organometallic chemistry and serve as useful reagents owing to their high compositional stabilities and accessible redox couples. ${ }^{1,2}$ Indeed, many chemists first encounter metallocenes in the context of their one-electron redox chemistry, with the $\mathrm{Cp}_{2} \mathrm{Fe}^{+/ 0}, \mathrm{Cp}_{2} \mathrm{Cr}^{+/ 0}$, and $\mathrm{Cp}_{2} \mathrm{Co}^{+/ 0}$ couples, and those of their related permethylated variants, being some of the most commonly exploited in all of synthetic chemistry. ${ }^{3}$

An area where divalent metallocene reductants (e.g., $\mathrm{Cp}_{2}{ }^{*} \mathrm{Cr}$, $\mathrm{Cp}_{2} * \mathrm{Co}$ ) have been proven particularly effective is catalytic $\mathrm{N}_{2}$-to- $\mathrm{NH}_{3}$ conversion $\left(\mathrm{N}_{2} \mathrm{RR}\right){ }^{4,5,6}$ Schrock first identified their utility in this context via the discovery of a molybdenum tris(amido)amine $\left(\left[\mathrm{HIPTN}_{3} \mathrm{~N}\right] \mathrm{Mo}, \mathrm{HIPTN}_{3} \mathrm{~N}=[(3,5-(2,4,6-\right.$ $\left.\left.\left.{ }^{i} \mathrm{Pr}_{3} \mathrm{C}_{6} \mathrm{H}_{2}\right)_{2} \mathrm{C}_{6} \mathrm{H}_{3} \mathrm{NCH}_{2} \mathrm{CH}_{2}\right)_{3} \mathrm{~N}\right]^{3-}$ ) $\mathrm{N}_{2} \mathrm{RR}$ catalyst system employing lutidinium as the acid and $\mathrm{Cp}_{2}{ }^{*} \mathrm{Cr}$ as the reductant. ${ }^{4}$ Since that discovery, other labs have exploited related cocktails that pair a metallocene reductant with an acid to drive $\mathrm{N}_{2} \mathrm{RR}$ using a range of metal catalysts, with selectivities and turnover numbers that continue to improve. ${ }^{5,6,7,8,9}$

The protonation chemistry of metallocenes is well studied, especially among Group $8^{10,11}$ and $10^{12,13}$ metallocenes. Related studies on more reducing Group 6 and 9 metallocenes (e.g., $\mathrm{Cp}_{2}{ }_{2} \mathrm{Cr}, \mathrm{Cp}_{2} \mathrm{Co}, \mathrm{Cp}_{2} \mathrm{Co}$ ), which are relevant to the aforementioned proton-coupled reduction of $\mathrm{N}_{2}$, have been much more limited. While studies have shown that the release of $\mathrm{H}_{2}$ is highly favorable on both thermodynamic and kinetic grounds, ${ }^{14}$ protonated Group 6 and 9 metallocene intermedi- ates have not been reliably identified and characterized. It has been presumed that the direct reactions of acids with reducing metallocenes are deleterious to selectivity for $\mathrm{N}_{2} \mathrm{RR}$ versus $\mathrm{H}_{2}$ generation. ${ }^{4,15}$

Our lab became interested in metallocenes following the observation that $\mathrm{Cp}_{2}{ }_{2} \mathrm{Co}$ could serve as the electron source for Fe-mediated $\mathrm{N}_{2} \mathrm{RR}$ in the presence of anilinium acids and an iron catalyst, $\mathrm{P}_{3}{ }^{\mathrm{B}} \mathrm{Fe}\left(\mathrm{P}_{3}{ }^{\mathrm{B}}=\right.$ tris(o-diisopropylphosphinophenyl)borane) ${ }^{8,9}$ Indeed, the selectivity for $\mathrm{N}_{2} \mathrm{RR}$ under these conditions proved far more efficient for $\mathrm{NH}_{3}$ formation (up to 78\%) than our originally published conditions using $\mathrm{KC}_{8}$ and $\left[\mathrm{H}\left(\mathrm{OEt}_{2}\right)_{2}\right]\left[\mathrm{BAr}_{4} \mathrm{~F}_{4} \quad\left(\mathrm{HBAr}_{4}, \quad \mathrm{BAr}_{4}=\right.\right.$ tetrakis $(3,5-$ bis(trifluoromethyl)phenyl)borate)). ${ }^{16,17}$ However, contrary to our mechanistic experiments with $\mathrm{HBAr}_{4}$, reaction of $\mathrm{P}_{3}{ }^{\mathrm{B}} \mathrm{FeN}_{2}{ }^{-}$with anilinium acids led neither to the observation of relevant intermediates (e.g., $\left.\mathrm{P}_{3}{ }^{\mathrm{B}} \mathrm{Fe}\left(\mathrm{NNH}_{2}\right)^{+}\right)$in freeze-quench spectroscopic methods, nor to the observation of fixed-N products upon annealing. ${ }^{9}, 18,19$

The apparent need for both acid and reductant to be present to achieve productive $\mathrm{N}-\mathrm{H}$ bond formation is reminiscent of Schrock and coworkers' observations when attempting to functionalize $\left[\mathrm{HIPTN}_{3} \mathrm{~N}\right] \mathrm{Mo}-\mathrm{N}_{2}$ with catalytically relevant reagents. ${ }^{20}$ In both cases, we have hypothesized that metallocene-mediated proton-coupled electron transfer reactions may play a key role in N-H bond-forming steps ${ }^{7,9,21}$ Furthermore, given the ubiquity of these metallocene reagents in $\mathrm{N}_{2} \mathrm{RR}$, we wondered whether metallocene-mediated $\mathrm{N}-\mathrm{H}$ bond forming steps might provide a contributing, or even dominant, mechanistic pathway. 
Density functional theory (DFT) studies by our group supported the notion that protonation of metallocenes such as $\mathrm{Cp}_{2}{ }^{*} \mathrm{Co}$ or $\mathrm{Cp}_{2} * \mathrm{Cr}$ by catalytically relevant acids is thermodynamically favorable. To our surprise, these DFT studies also predicted that ring protonation is thermodyamically favored versus protonation at the metal (to form a hydride). ${ }^{8}$ Such selectivity would contrast with the classic case of ferrocene, where protonation at iron has been firmly established. ${ }^{10,22} \mathrm{The}^{\mathrm{C}} \mathrm{Cp}_{2}{ }^{*} \mathrm{Co}$ and $\mathrm{Cp}_{2}{ }_{2} \mathrm{Cr}$ ring-protonated species are predicted to have remarkably weak $\mathrm{C}-\mathrm{H}$ bond dissociation enthalpies (BDE $<37 \mathrm{kcal}$ $\mathrm{mol}^{-1}$ ), which should in turn make them excellent PCET donors. ${ }^{7,9}$ These observations intimate that protonated metallocene intermediates might thereby offer viable pathways for $\mathrm{N}-$ $\mathrm{H}$ bond formation via PCET (or even hydride transfer; vide infra), in addition to the more commonly presumed pathway for deleterious $\mathrm{H}_{2}$ evolution (Figure 1).

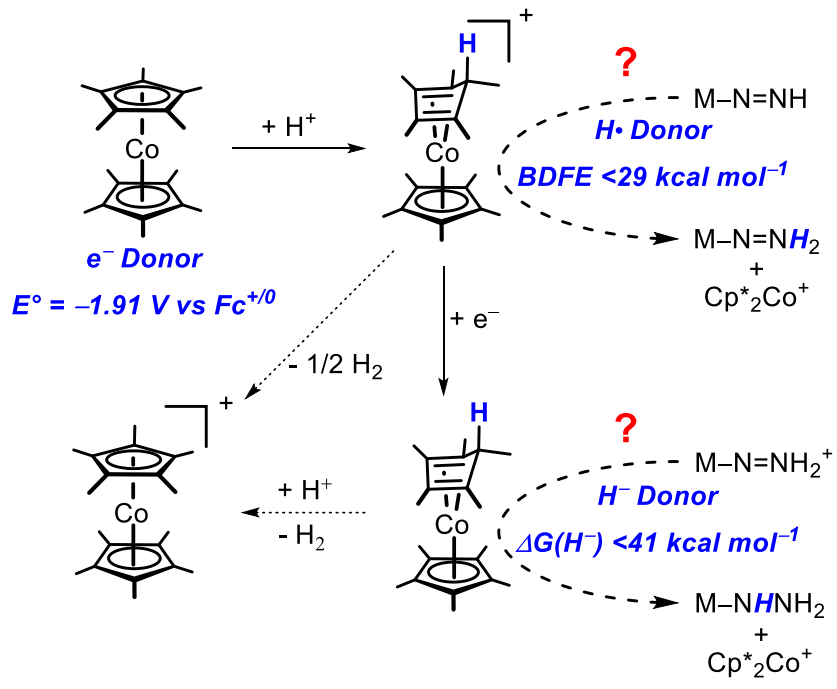

Figure 1: Reaction pathways to consider for protonated $\mathrm{Cp}_{2}{ }_{2} \mathrm{Co}$ species, illustrating both undesired HER and possible $\mathrm{N}-\mathrm{H}$ bond forming steps relevant to $\mathrm{N}_{2} \mathrm{RR}$

We previously reported preliminary investigations into the protonation of $\mathrm{Cp}^{*} \mathrm{Co}$. In brief, slow addition of a toluene solution of $\mathrm{Cp}^{*}{ }_{2} \mathrm{Co}$ to a vigorously stirred suspension of trifluoromethanesulfonic acid (HOTf) in toluene at $-78{ }^{\circ} \mathrm{C}$ led to precipitation of a purple solid that could be isolated via filtration. On the basis of the $\mathrm{X}$-band continuous wave $(\mathrm{CW})$ electron paramagnetic resonance (EPR) spectrum (77 K, Figure 4) of the solid, we speculated that it was a protonated $\mathrm{Cp}^{*}{ }_{2} \mathrm{Co}$ species. ${ }^{8}$ Herein, we undertake the rigorous characterization of the protonation products of $\mathrm{Cp}^{*}{ }_{2} \mathrm{Co}$ using pulse EPR techniques, and provide unequivocal evidence for the assignment of the ring protonated isomers $\mathrm{Cp}^{*}\left(\right.$ exolendo $\left.-\eta^{4}-\mathrm{C}_{5} \mathrm{Me}_{5} \mathrm{H}\right) \mathrm{Co}^{+}$. Variable temperature Q-Band $(34 \mathrm{GHz})$ pulse EPR spectroscopy, in conjunction with DFT predictions, are key to enabling the assignment. We also demonstrate that exo-protonation can be favored when using a bulkier acid. Of further interest, we provide physical data to experimentally assess the $\mathrm{C}-\mathrm{H}$ bond dissociation free energy $\left(\mathrm{BDFE}_{\mathrm{C}-\mathrm{H}}\right)$ for $\mathrm{Cp} *\left(\right.$ exo- $\eta^{4}-$ $\left.\mathrm{C}_{5} \mathrm{Me}_{5} \mathrm{H}\right) \mathrm{Co}^{+}$, which support our earlier DFT predictions that it has an exceptionally weak $\mathrm{C}-\mathrm{H}$ bond (Figure 1). This behavior should not be limited to the present protonated metallocene, and we thus outline a general approach to understanding the reactivity of arene-protonated metal species.
2.1 Pulse Electron Paramagnetic Resonance Spectroscopy on Protonated $\mathrm{Cp}^{*}{ }_{2} \mathrm{Co}$. To interrogate the reaction of Cp* ${ }_{2}$ Co with HOTf, we employed Q-band pulse EPR experiments at very low temperatures. Electron spin-echo (ESE) detected, field-swept spectra at Q-band, performed at $6 \mathrm{~K}$ and $10 \mathrm{~K}$, clearly identify the presence of two different species with dramatically different $\mathrm{g}$-anisotropy in the precipitated solid (Figure 2). Fortuitously, measurement of the approximate spin-lattice relaxation rates via inversion recovery (see SI) reveals that the two species have significantly different $T_{1}$, times. The species with higher $\mathbf{g}$-anisotropy $(\mathbf{g}=[2.625,2.349$, 1.984]) exhibits a much shorter $T_{1}$ ' than the species exhibiting a narrower spectrum $(\mathbf{g}=[2.170,2.085,2.005])$, even at $6 \mathrm{~K}$. This difference in relaxation rates becomes more dramatic upon warming the sample to $10 \mathrm{~K}$; at this temperature, $T_{1}$ ' for the species with high g-anisotropy is short enough to greatly diminish its electron-nuclear double resonance (ENDOR) response relative to the other species, even at magnetic fields with significant spectral overlap. Thus, the signals arising from these two species in pulse EPR experiments can be largely isolated by recording spectra at these two different temperatures (6 K and $10 \mathrm{~K}$; Figure 2).

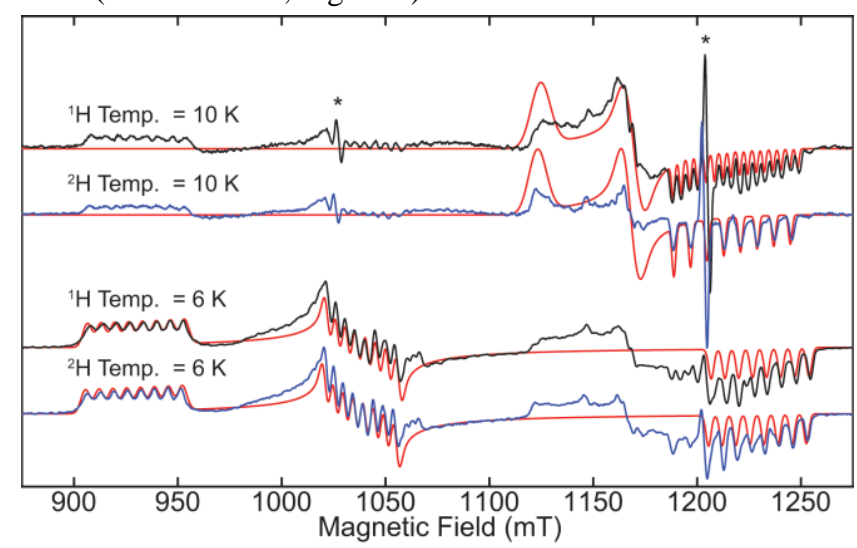

Figure 2: Pseudomodulated ${ }^{23}$ Q-band ESE-detected EPR spectra of the reaction of $\mathrm{Cp}_{2}{ }_{2} \mathrm{Co}$ with HOTf (black traces), and DOTf (blue traces) measured at $10 \mathrm{~K}$ (top traces) and $6 \mathrm{~K}$ (bottom traces). See SI for acquisition parameters. Simulations for each species are displayed in red (See SI for simulation details). The sharp signals with asterisks above them are due to a background signal arising from a component of the EPR cavity (See SI for more detail).

For the narrower, more slowly relaxing species, a comparison of the Q-band ESE-detected EPR spectra from the reaction of Cp ${ }_{2}$ Co with HOTf and DOTf shows a clear change, from 16 resolved splittings centered at $1270 \mathrm{mT}$, to the 8 lines expected for a large hyperfine coupling to an $I=7 / 2{ }^{59} \mathrm{Co}$ nucleus $\left(A\left({ }^{59} \mathrm{Co}\right)_{10 \mathrm{~K}}=[15,15,225] \mathrm{MHz}\right)$. This observation indicates that, at least at the orientation corresponding to $\mathbf{g}_{3}$, there is a single ${ }^{1} \mathrm{H}$ nucleus with a hyperfine coupling of approximately $1 / 2$ of the magnitude of the ${ }^{59}$ Co hyperfine coupling.

Analysis of the field-dependent ${ }^{1} \mathrm{H}$ ENDOR (Figure 3a-b) at $10 \mathrm{~K}$, with corroboration from ${ }^{2} \mathrm{H}$ hyperfine sub-level correlation (HYSCORE) spectra (see SI) of each respective species, allows determination of the full hyperfine tensor of this acidderived proton: $A\left({ }^{1} \mathrm{H}\right)_{10 \mathrm{~K}}=[106.5,112.5,108.2] \mathrm{MHz}$, with $a_{\text {iso }}=109.1 \mathrm{MHz}$. Comparing this value to that known for the hydrogen atom $(1420 \mathrm{MHz})$ indicates that approximately 0.08 $\mathrm{e}^{-}$are localized on this proton. ${ }^{24}$ The amount of spin density localized on this proton is unusually large, even when compared with highly reactive, paramagnetic transition metal hydrides. ${ }^{25}$

Characterization of the species with greater g-anisotropy was targeted by performing analogous experiments at $6 \mathrm{~K}$. In this

\section{RESULTS}


case, the Q-band ESE-detected EPR spectra for this species in samples generated with HOTf and DOTf are indistinguishable, indicating that the ${ }^{1} \mathrm{H}$ hyperfine coupling to the acid-derived proton is small in comparison to the ${ }^{59} \mathrm{Co}$ hyperfine and the inhomogeneous line broadening. This was confirmed via fielddependent ENDOR (Figure 3c-d) and HYSCORE (see SI) spectra acquired at $6 \mathrm{~K}$, which reveal a single acid-derived proton coupling of $A\left({ }^{1} \mathrm{H}\right)_{6 \mathrm{~K}}=[19.0,15.0,19.5] \mathrm{MHz}, a_{i s o}=$ $17.8 \mathrm{MHz}$
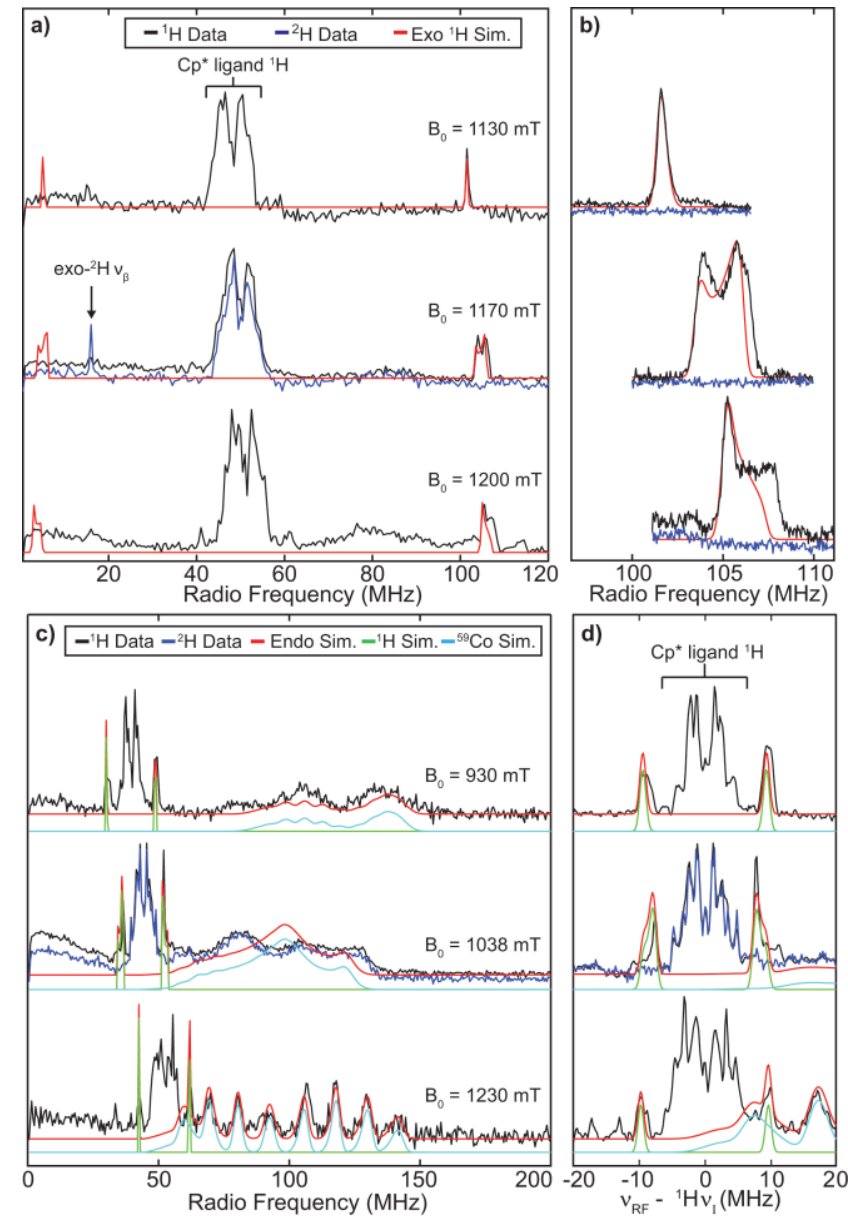

Figure 3: a) Q-band Davies ENDOR spectra at $10 \mathrm{~K}$ and b) narrow Qband Davies ENDOR spectra at $10 \mathrm{~K}$. c) Q-band Davies ENDOR spectra at $6 \mathrm{~K}$ and d) narrow Q-band Davies ENDOR spectra at $6 \mathrm{~K}$. Data from the reaction with HOTf (black) and DOTf (blue) are shown. A simulation (red) is given and in the spectra at $6 \mathrm{~K}$ the simulation is further decomposed into the components for the ${ }^{1} \mathrm{H}$ simulation (green) and the ${ }^{59} \mathrm{Co}$ simulation (light blue). See SI for full acquisition parameters and simulation details.

Additionally, features from ${ }^{59} \mathrm{Co}\left(A\left({ }^{59} \mathrm{Co}\right)_{6 \mathrm{~K}}=[245,160,187]\right.$ $\mathrm{MHz}$ ) are observable in the ENDOR spectra at all fields, which is likely due to the more isotropic nature of the coupling symmetry of this species in comparison to the species with smaller g-anisotropy. In the ENDOR acquired at $1230 \mathrm{mT}$, additional splittings due to the ${ }^{59} \mathrm{Co}$ nuclear quadrupole interaction are resolved. Simulations of these ENDOR spectra indicate a quadrupole coupling constant of $e^{2} q Q / h=170 \mathrm{MHz}$, with negligible electric field gradient rhombicity $(\eta)$. These values are very similar to those reported for $\mathrm{Cp}_{2} \mathrm{Co}^{+}\left(e^{2} q Q / h=\right.$ 171.5 $\mathrm{MHz}$ and $\eta=0$ ), as determined by nuclear quadrupole resonance. This suggests that protonation results in only a relatively minor perturbation of the environment around $\mathrm{Co}^{26}$

\subsection{Stereochemical Assignment of $\mathrm{Cp}_{2}{ }_{2} \mathrm{Co}$ Protonation.}

Notably, both of the proton hyperfine coupling tensors are highly isotropic in nature, with only small anisotropic compo- nents $\left(T\left({ }^{1} \mathrm{H}\right)_{10 \mathrm{~K}}=[-2.6,3.4,-0.9] \mathrm{MHz} ; T\left({ }^{1} \mathrm{H}\right)_{6 \mathrm{~K}}=[1.2,-2.8\right.$, 1.7] $\mathrm{MHz}$ ). To evaluate possible chemical assignments for these observations, DFT calculations were performed to optimize the structure of the three plausible protonation isomers (i.e., $\mathrm{Co}-\mathrm{H}, e x o-\mathrm{C}-\mathrm{H}$, and endo-C-H) and then single point calculations were performed to predict the relevant hyperfine tensors (Figure 5a). ${ }^{27}$ Consistent with previous experimental observations for paramagnetic transition metal hydrides, DFT predicts the $\mathrm{Co}-\mathrm{H}$ isomer to have a large, roughly axial dipolar coupling tensor $\left.\left(T\left({ }^{1} \mathrm{H}\right)_{\mathrm{Co}-\mathrm{H}}=[34.1,-20.7,-12.9]\right)\right)^{28,29}$ Furthermore, the predicted $a_{i s o}$ value for the $\mathrm{Co}-\mathrm{H}$ of $-50 \mathrm{MHz}$ is inconsistent with our experimental EPR data for the protonated species. In contrast, the hyperfine coupling tensor for both exo- and endo-isomers are predicted to be far more isotropic $\left(T\left({ }^{1} \mathrm{H}\right)_{\text {exo-C-H }}=[-2.4,3.8,-1.4]\right.$ and $T\left({ }^{1} \mathrm{H}\right)_{\text {endo- } \mathrm{C}-\mathrm{H}}=[-3.1,8.7$, $-5.6])$, consistent with the EPR data available. Importantly, our DFT calculations also predict that the two ring-protonated isomers have very different $a_{\text {iso }}$ values, with the exo-isomer predicted to have $a_{\text {iso }}=119 \mathrm{MHz}$ and the endo-isomer predicted to have $a_{\text {iso }}=31 \mathrm{MHz}$. Thus, we assign the species with small g-anisotropy to be the exo-isomer and that with large $\mathbf{g}$ anisotropy to be the endo-isomer.

Assuming this assignment is correct then, on the basis of the recorded CW EPR spectra, the endo-isomer is formed in higher yield with HOTf (Figure 4, top). We wondered whether it might be possible to achieve preferential exo-functionalization by using a bulkier acid. Indeed, we have found that slow addition of a toluene solution of $\mathrm{Cp}^{*}{ }_{2} \mathrm{Co}$ at $-78{ }^{\circ} \mathrm{C}$ to a rapidly stirred suspension of the more sterically encumbered bis(trifluoromethane)sulfonimide $\left(\mathrm{HNTf}_{2}\right)$ in toluene also precipitates a purple solid (Figure 4, bottom). Analysis of this solid by CW X-Band EPR at $77 \mathrm{~K}$ reveals a near complete
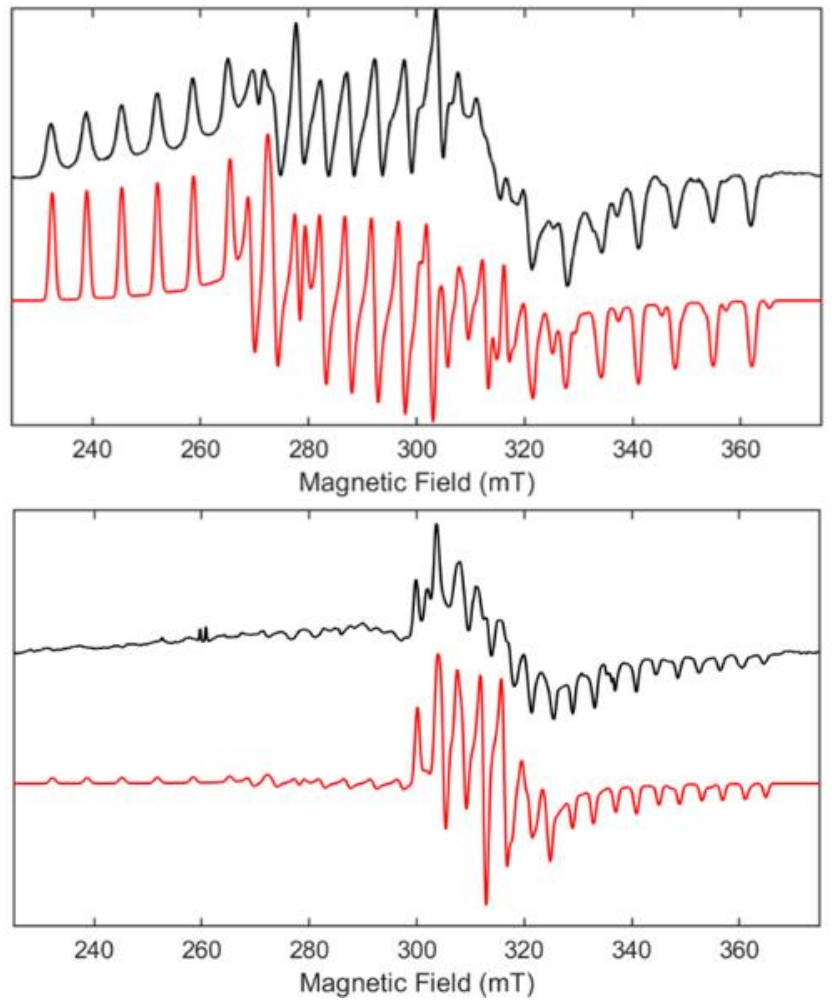

Figure 4: (top) X-Band CW EPR spectrum of the reaction of $\mathrm{Cp} *{ }_{2} \mathrm{Co}$ with HOTf (black) and its simulation (red). (bottom) X-Band CW EPR spectrum of the reaction of $\mathrm{Cp}_{2}{ }_{2} \mathrm{Co}$ with $\mathrm{HNTf}_{2}$ (black) and its simulation (red). The simulations are generated using the same parameters (see SI) except for the weighting of the two species. For the top simulation it is 10:1 endo:exo and in the bottom simulation it is $3: 10$ endo:exo. 
a)

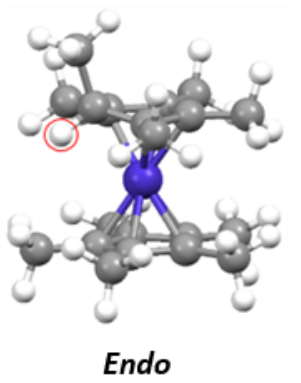

$\mathrm{G}_{\mathrm{rel}}=0 \mathrm{kcal} \mathrm{mol}^{-1}$

BDFE $=24 \mathrm{kcal} \mathrm{mol}^{-1}$

$a\left({ }^{1} \mathrm{H}\right)_{\text {iso }}=31 \mathrm{MHz}$

$\boldsymbol{T}\left({ }^{1} \mathrm{H}\right)=[-3.1,8.7,-5.6]$

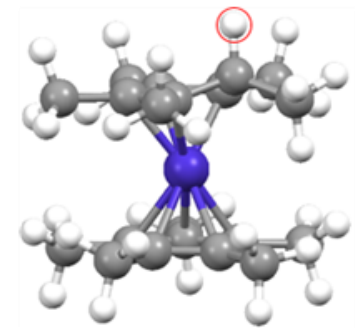

Exo

$\mathrm{G}_{\text {rel }}=+2 \mathrm{kcal} \mathrm{mol}^{-1}$

BDFE $=22 \mathrm{kcal} \mathrm{mol}^{-1}$

$a\left({ }^{1} \mathrm{H}\right)_{\text {iso }}=119 \mathrm{MHz}$

$\boldsymbol{T}\left({ }^{1} \mathrm{H}\right)=[-2.4,3.8,-1.4]$

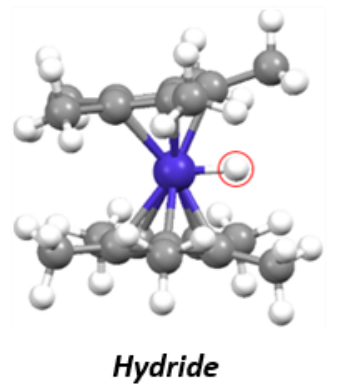

$\mathrm{G}_{\mathrm{rel}}=+17 \mathrm{kcal} \mathrm{mol}^{-1}$

BDFE $=7 \mathrm{kcal} \mathrm{mol}^{-1}$

$a\left({ }^{1} \mathrm{H}\right)_{\text {iso }}=-51 \mathrm{MHz}$

$\boldsymbol{T}\left({ }^{1} \mathrm{H}\right)=[34.1,-20.7,-12.9]$

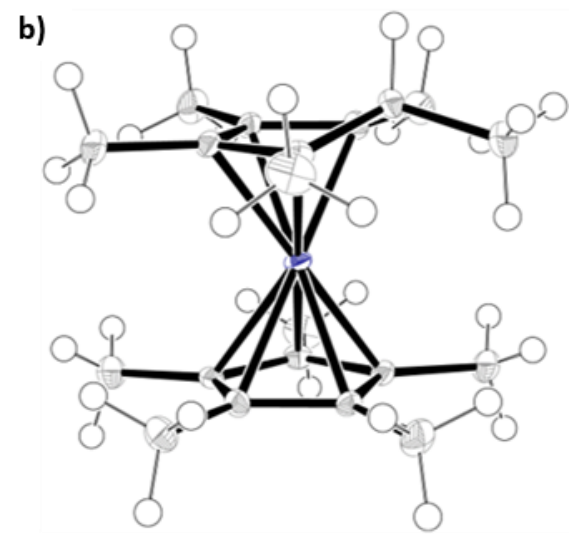

\section{c) Experimental EPR/ENDOR ${ }^{1} \mathrm{H}$ Simulation parameters for Endo- and Exo-protonation products of $\mathrm{Cp}^{*}{ }_{2} \mathrm{Co}$}

\begin{tabular}{c|cccc} 
Site of Protonation & g-tensor & $\boldsymbol{A}(\mathbf{M H z})$ & $\boldsymbol{a}_{\mathrm{iso}}(\mathbf{M H z})$ & $\boldsymbol{T}(\mathbf{M H z})$ \\
\hline Exo & {$[2.170,2.085,2.005]$} & {$[106.5,112.5,108.2]$} & 109.1 & {$[-2.6,3.4,-0.9]$} \\
\hline Endo & {$[2.626,2.349,1.984]$} & {$[19.0,15.0,19.5]$} & 17.8 & {$[1.2,-2.8,1.7]$} \\
\hline
\end{tabular}

$$
a_{\text {iso }}=\left(\boldsymbol{A}_{1}+\boldsymbol{A}_{2}+\boldsymbol{A}_{3}\right) / 3 ; T=\left[\boldsymbol{A}_{1}-a_{\text {iso }}, \boldsymbol{A}_{2}-a_{\text {iso }}, \boldsymbol{A}_{3}-a_{\text {iso }}\right]
$$

Figure 5: a) DFT optimized structures for the protonated form of $\mathrm{Cp}_{2}{ }_{2} \mathrm{Co}$. The predicted $A\left({ }^{1} \mathrm{H}\right)$ values are for the proton circled in red. b) X-ray crystal structure of $\mathrm{Cp} *\left(e x o-\eta^{4}-\mathrm{C}_{5} \mathrm{Me}_{5} \mathrm{H}\right) \mathrm{Co}$. Thermal ellipsoids are shown at 50\% probability. c) Experimentally derived ${ }^{1} \mathrm{H}$ hyperfine parameters for the endo- and exo-isomers of protonated $\mathrm{Cp}_{2}{ }_{2} \mathrm{Co}$.

inversion of the protonation-site selectivity. Both of the protonation reactions are under kinetic control due to the rapid precipitation upon proton transfer. With the smaller HOTf, endoprotonation is preferred (Figure 5a), but with the bulkier $\operatorname{HNTf}_{2}$, steric clash with the opposite Cp* ring leads to exoprotonation being favored (Figure $5 b$ ).

Further chemical confirmation of the protonation site was obtained by pre-functionalization of the $\mathrm{Cp}^{*}$ ring. Taking a cue from classic literature, we noted that Wilkinson et al. previously characterized a far more stable, neutral ringfunctionalized species, $\mathrm{Cp}\left(\eta^{4}-\mathrm{C}_{5} \mathrm{H}_{6}\right) \mathrm{Co}^{30}$ By analogy to their approach, we generated $\mathrm{Cp} *\left(e x o-\eta^{4}-\mathrm{C}_{5} \mathrm{Me}_{5} \mathrm{H}\right) \mathrm{Co}$ in moderate yield via the reaction of $\mathrm{Cp}_{2}{ }_{2} \mathrm{Co}^{+}$with excess tetrabutylammonium borohydride in refluxing THF. The stereospecificity of exo-functionalization could be confirmed in the solid state by XRD analysis (Figure $5 \mathrm{~b}$ ) and in solution via NMR spectroscopy.

Although our efforts to use common oxidants (i.e., $\mathrm{Fc}^{+}, \mathrm{Ag}^{+}$) to affect the electron transfer were unsuccessful, we found that $\mathrm{Cp} *\left(\right.$ exo $\left.-\eta^{4}-\mathrm{C}_{5} \mathrm{Me}_{5} \mathrm{H}\right) \mathrm{Co}$ could be oxidized by reaction with $\mathrm{HBAr}_{4}{ }_{4}$ at $-78{ }^{\circ} \mathrm{C}$ in pentane. The purple precipitate was analyzed by X-Band CW EPR and, as expected, demonstrated only the signal that we had assigned to the exo-isomer. To confirm that the strongly coupled proton observed derived from our pre-functionalized ring and not the acid, $\mathrm{Cp}^{*}\left(\mathrm{exo}-\eta^{4}\right.$ $\left.\mathrm{C}_{5} \mathrm{Me}_{5} \mathrm{D}\right) \mathrm{Co}$ was reacted with $\mathrm{HBAr}_{4}{ }_{4}$. Only the formation of $\mathrm{Cp} *\left(\right.$ exo- $\left.\eta^{4}-\mathrm{C}_{5} \mathrm{Me}_{5} \mathrm{D}\right) \mathrm{Co}^{+}$was detected by EPR (Scheme 1, see $\mathrm{SI})$.

2.3 Thermochemical Measurements. We were also interested in experimentally validating the DFT-predicted thermochemical properties of these species. The high kinetic instability of $\mathrm{Cp} *\left(e x o / e n d o-\eta^{4}-\mathrm{C}_{5} \mathrm{Me}_{5} \mathrm{H}\right) \mathrm{Co}^{+}$in solution precludes direct measurement of the thermochemical properties that we have predicted by DFT. Of particular interest is experimental validation of a remarkably weak $\mathrm{BDFE}_{\mathrm{C}-\mathrm{H}}$. We therefore

\section{Scheme 1. Proposed Mechanism for the Oxidation of $\mathrm{Cp}^{*}\left(\boldsymbol{e x o}-\eta^{4}-\mathrm{C}_{5} \mathrm{Me}-\mathrm{D}\right) \mathrm{Co}$ with $\mathrm{HBAr}^{\mathrm{F}_{4}}$}
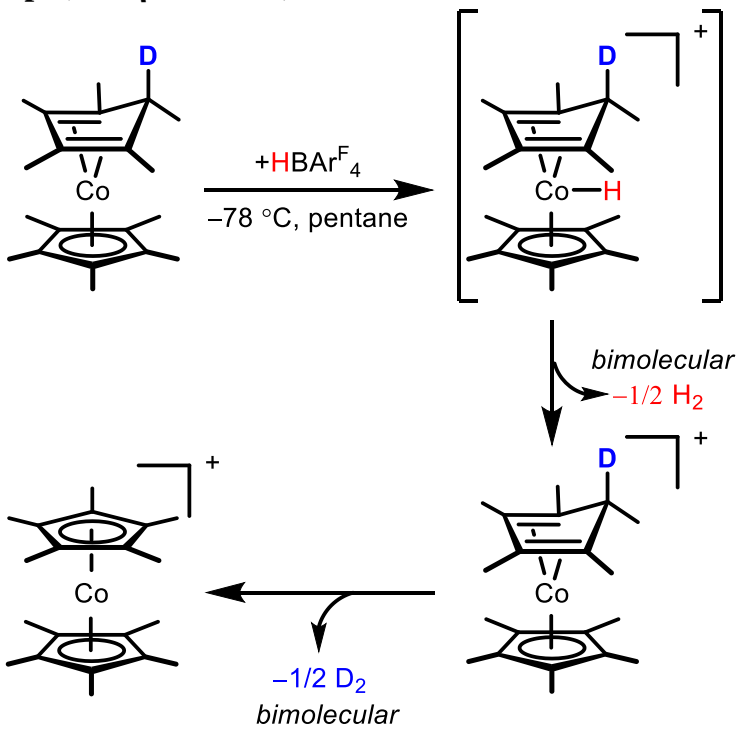

bimolecular

turned to the neutral species $\mathrm{Cp}^{*}\left(\right.$ exo- $\left.\eta^{4}-\mathrm{C}_{5} \mathrm{Me}_{5} \mathrm{H}\right) \mathrm{Co}$ as a means to indirectly measure pertinent thermochemical properties for $\mathrm{Cp}^{*}\left(\right.$ exo- $\left.\eta^{4}-\mathrm{C}_{5} \mathrm{Me}_{5} \mathrm{H}\right) \mathrm{Co}^{+}$.

One important parameter in this regard is the $\mathrm{Cp}^{*}\left(\right.$ exo- $\eta^{4}$ $\left.\mathrm{C}_{5} \mathrm{Me}_{5} \mathrm{H}\right) \mathrm{Co}^{+/ 0}$ redox couple. In cyclic voltammograms $(\mathrm{CVs})$ of $\mathrm{Cp} *\left(e x o-\eta^{4}-\mathrm{C}_{5} \mathrm{Me}_{5} \mathrm{H}\right) \mathrm{Co}$, obtained at typical scan rates $(0.01$ to $1.0 \mathrm{~V} \mathrm{~s}^{-1}$ ) at room temperature in butyronitrile, ${ }^{31}$ only an irreversible oxidation is observed. Continuing to scan these voltammograms further in the cathodic direction leads to the observation of the fully reversible $\mathrm{Cp}_{2}{ }_{2} \mathrm{Co}^{+/ 0}$ couple (Figure 6, top), consistent with the loss of 0.5 equivalents of $\mathrm{H}_{2}$, as expected from $\mathrm{Cp}^{*}\left(\right.$ exo- $\left.\eta^{4}-\mathrm{C}_{5} \mathrm{Me}_{5} \mathrm{H}\right) \mathrm{Co}^{+}$in solution. By scanning rapidly $\left(>10 \mathrm{~V} \mathrm{~s}^{-1}\right.$ ) at room temperature (Figure 6 , bottom), or alternatively by cooling the reaction mixture to $-78{ }^{\circ} \mathrm{C}$ (see SI), voltammograms with appreciable reversibility could be 
obtained, from which $E^{0}$ could be determined to be $-0.62 \mathrm{~V}$ vs $\mathrm{Fc}^{+/ 0}$ (Figure 7).
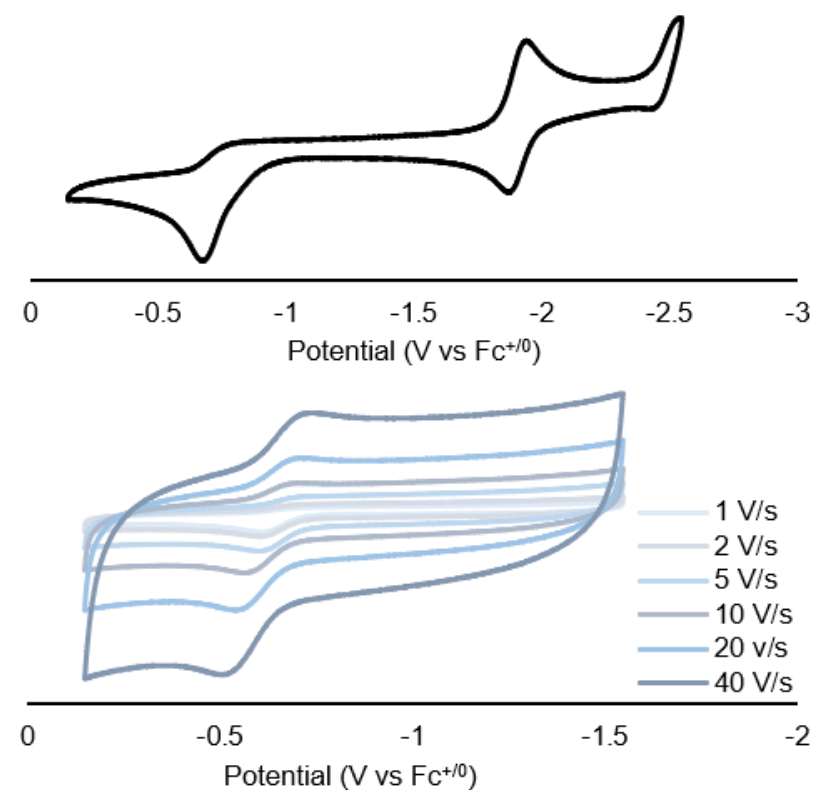

Figure 6: Cyclic voltammograms of the $\mathrm{Cp} *\left(\right.$ exo- $\left.\eta^{4}-\mathrm{C}_{5} \mathrm{Me}_{5} \mathrm{H}\right) \mathrm{Co}^{+/ 0}$ couple at room temperature in a $0.4 \mathrm{M}\left[\mathrm{TBA}^{2}\left[\mathrm{PF}_{6}\right]\right.$ solution of butyronitrile. (top) Scan showing that the oxidation of $\mathrm{Cp}^{*}\left(\right.$ exo- $\left.-\eta^{4}-\mathrm{C}_{5} \mathrm{Me}_{5} \mathrm{H}\right) \mathrm{Co}^{0}$ leads to the emergence of the $\mathrm{Cp}_{2}{ }_{2} \mathrm{Co}^{+/ 0}$ couple. (bottom) Variable scan rate measurements on the $\mathrm{Cp} *\left(\right.$ exo- $\left.\eta^{4}-\mathrm{C}_{5} \mathrm{Me}_{5} \mathrm{H}\right) \mathrm{Co}^{+/ 0}$ feature.

To further confirm this value, the methylated derivative, $\mathrm{Cp} *\left(\eta^{4}-\mathrm{C}_{5} \mathrm{Me}_{6}\right) \mathrm{Co}$, was prepared. ${ }^{13}$ The oxidation event for this species is reversible. ${ }^{32}$ This result is consistent with the significantly higher kinetic barrier anticipated for $\mathrm{Me}$ • loss/transfer compared to $\mathrm{H} \bullet$ loss/transfer. In acetonitrile, the $E^{0}$ we measure for $\mathrm{Cp}^{*}\left(\eta^{4}-\mathrm{C}_{5} \mathrm{Me}_{6}\right) \mathrm{Co}^{+/ 0}$ is $-0.61 \mathrm{~V} \mathrm{vs} \mathrm{Fc}^{+/ 0}$, in good agreement with our experimental data for the $\mathrm{Cp}^{*}($ exo$\left.\eta^{4}-\mathrm{C}_{5} \mathrm{Me}_{5} \mathrm{H}\right) \mathrm{Co}^{+/ 0}$ couple.

An estimate of the hydricity $\left(\Delta G\left(\mathrm{H}^{-}\right)\right)$of $\mathrm{Cp}^{*}\left(\right.$ exo- $\eta^{4}$ $\left.\mathrm{C}_{5} \mathrm{Me}_{5} \mathrm{H}\right)$ Co provides another useful parameter. Dissolution of $\mathrm{Cp} *\left(\right.$ exo- $\left.\eta^{4}-\mathrm{C}_{5} \mathrm{Me}_{5} \mathrm{H}\right) \mathrm{Co}$ in $\mathrm{MeCN}-d_{3}$ and reaction with $1 \mathrm{~atm}$ of $\mathrm{CO}_{2}$ or with excess $\left[\mathrm{Pt}(\mathrm{dmpe})_{2}\right]^{2+}(\mathrm{dmpe}=1,2-$ dimethylphosphinoethane), leads in both cases to quantitative hydride transfer. From this observation we can determine a lower bound for the hydricity of $\mathrm{Cp}^{*}\left(\right.$ exo $\left.-\eta^{4}-\mathrm{C}_{5} \mathrm{Me}_{5} \mathrm{H}\right) \mathrm{Co}$ $\left(\Delta G\left(\mathrm{H}^{-}\right)<41 \mathrm{kcal} \mathrm{mol}^{-1}\right.$; Figure 7). ${ }^{33}$ This is in good agreement with our DFT prediction of $\Delta G\left(\mathrm{H}^{-}\right)=37 \mathrm{kcal} \mathrm{mol}^{-1}$ for this species. The $\mathrm{C}-\mathrm{H}$ bond of $\mathrm{Cp} *\left(\right.$ exo- $\left.\eta^{4}-\mathrm{C}_{5} \mathrm{Me}_{5} \mathrm{H}\right) \mathrm{Co}$ is thus about $15 \mathrm{kcal} \mathrm{mol}^{-1}$ more hydridic than the $\mathrm{C}-\mathrm{H}$ bonds in the common biological hydride donors $\mathrm{NADH}$ and NADPH. ${ }^{34}$ These observations hint at the possibility that, at least in principle, species such as $\mathrm{Cp} *\left(\right.$ exo- $\left.\eta^{4}-\mathrm{C}_{5} \mathrm{Me}_{5} \mathrm{H}\right)$ Co could mediate hydride transfer steps relevant to $\mathrm{N}_{2} \mathrm{RR}$, such as that shown in Figure 1.

In an attempt to estimate the homolytic $\mathrm{C}-\mathrm{H}$ bond strength (BDFE) of $\mathrm{Cp} *\left(\right.$ exo- $\left.\eta^{4}-\mathrm{C}_{5} \mathrm{Me}_{5} \mathrm{H}\right) \mathrm{Co}$, it was reacted with excess 4-methoxy-2,2,6,6-tetramethyl-1-piperidinyloxy ${ }^{\mathrm{MeO}}$ TEMPO•). To our surprise, two equivalents of ${ }^{4-}$ ${ }^{\mathrm{MeO}} \mathrm{TEMPO}-\mathrm{H}$ were formed. The first equivalent derives from the expected $\mathrm{H}$-atom abstraction to form $\mathrm{Cp}^{*}{ }_{2} \mathrm{Co}$, providing an upper limit to the $\mathrm{BDFE}_{\text {exo-C-H}}:<65 \mathrm{kcal} \mathrm{mol}^{-1}$ (eq 1, Figure 7). ${ }^{24}$ The second ${ }^{4-\mathrm{MeO}} \mathrm{TEMPO}-\mathrm{H}$ equiv is derived from a second $\mathrm{H}$-atom abstraction step between ${ }^{4-\mathrm{MeO}}$ TEMPO $\bullet$ and $\mathrm{Cp}^{*}{ }_{2} \mathrm{Co}$ (eq 2). This generates the known fulvene species, $\mathrm{Cp} *\left(\eta^{4}-\mathrm{C}_{5} \mathrm{Me}_{4} \mathrm{CH}_{2}\right) \mathrm{Co}^{35}$ These observations are consistent with our $\mathrm{BDFE}_{\mathrm{C}-\mathrm{H}}$ predictions for the $\mathrm{C}-\mathrm{H}$ bond in both
$\mathrm{Cp}^{*}\left(\right.$ exo- $\left.\eta^{4}-\mathrm{C}_{5} \mathrm{Me}_{5} \mathrm{H}\right) \mathrm{Co}$ and $\mathrm{Cp}^{*}{ }_{2} \mathrm{Co}\left(53\right.$ and $62 \mathrm{kcal} \mathrm{mol}^{-1}$, respectively).

$$
\begin{aligned}
& \mathrm{Cp} *\left(\text { exo- } \eta^{4}-\mathrm{C}_{5} \mathrm{Me}_{5} \mathrm{H}\right) \mathrm{Co}+{ }^{4 \mathrm{MeO}} \mathrm{TEMPO} \cdot \rightarrow \\
& \mathrm{Cp}^{*}{ }_{2} \mathrm{Co}+{ }^{4 \mathrm{MeO}} \mathrm{TEMPO}-\mathrm{H} \\
& \mathrm{Cp} *{ }_{2} \mathrm{Co}+{ }^{4 \mathrm{MeO} \mathrm{TEMPO} \cdot \rightarrow}+\underset{ }{\mathrm{Cp} *\left(\eta^{4}-\mathrm{C}_{5} \mathrm{Me}_{4} \mathrm{CH}_{2}\right) \mathrm{Co}+{ }^{4 \mathrm{MeO}} \text { TEMPO-H }}
\end{aligned}
$$

With this thermochemical data for $\mathrm{Cp}^{*}\left(\right.$ exo $\left.-\eta^{4}-\mathrm{C}_{5} \mathrm{Me}_{5} \mathrm{H}\right) \mathrm{Co}$ in hand, it is possible to constrain the $\mathrm{BDFE}_{\mathrm{C}-\mathrm{H}}$ for $\mathrm{Cp}^{*}\left(\right.$ exo- $\eta^{4}$ $\left.\mathrm{C}_{5} \mathrm{Me}_{5} \mathrm{H}\right) \mathrm{Co}^{+}$. Using the bound established for the $\mathrm{BDFE}_{\mathrm{C}-\mathrm{H}}$ for neutral $\mathrm{Cp} *\left(\right.$ exo- $\left.\eta^{4}-\mathrm{C}_{5} \mathrm{Me}_{5} \mathrm{H}\right) \mathrm{Co}$, we can establish an upper limit for the $\mathrm{BDFE}_{\mathrm{C}-\mathrm{H}}$ of $\mathrm{Cp} *\left(\right.$ exo- $\left.\eta^{4}-\mathrm{C}_{5} \mathrm{Me}_{5} \mathrm{H}\right) \mathrm{Co}^{+}$of $34 \mathrm{kcal}$ $\mathrm{mol}^{-1}$. But using the upper limit determined for the $\Delta G\left(\mathrm{H}^{-}\right)$of $\mathrm{Cp} *\left(\right.$ exo- $\left.\eta^{4}-\mathrm{C}_{5} \mathrm{Me}_{5} \mathrm{H}\right) \mathrm{Co}$ allows us to place an even lower upper limit for $\mathrm{BDFE}\left(\mathrm{Cp} *\left(\right.\right.$ exo $\left.\left.-\eta^{4}-\mathrm{C}_{5} \mathrm{Me}_{5} \mathrm{H}\right) \mathrm{Co}^{+}\right)$of $<29 \mathrm{kcal}$ $\mathrm{mol}^{-1}$. This experimental upper limit predicted from the solution phase data is in reasonable agreement with our gas-phase DFT prediction of $23 \mathrm{kcal} \mathrm{mol}^{-1}$. ${ }^{36}$ The $\mathrm{C}-\mathrm{H}$ bond of $\mathrm{Cp}^{*}($ exo$\left.\eta^{4}-\mathrm{C}_{5} \mathrm{Me}_{5} \mathrm{H}\right) \mathrm{Co}^{+}$is extremely weak.

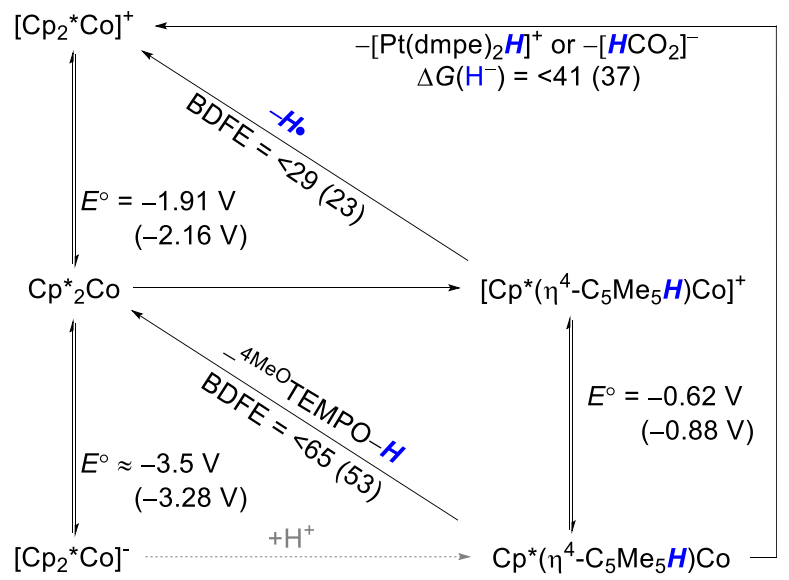

Figure 7: Thermochemistry of neutral and cationic $\mathrm{Cp} *\left(\right.$ exo- $\eta^{4}-$ $\left.\mathrm{C}_{5} \mathrm{Me}_{5} \mathrm{H}\right) \mathrm{Co}$. Computational values are shown in parentheses. Thermodynamic quantities are in $\mathrm{kcal} \mathrm{mol}^{-1}$ and potentials are against $\mathrm{Fc}^{+/ 0}$.

\section{DISCUSSION}

It is well established that group 8 metallocenes form metal hydrides upon protonation. ${ }^{10,11,22}$ In the case of ferrocene, computational trajectories have been used to argue that there is fast exchange between a terminal hydride and a hydride that forms an agostic interaction with the Cp ring. ${ }^{37,38}$ In contrast, neutral group 10 metallocenes $\left(\mathrm{Cp}_{2} \mathrm{Ni}\right.$ and $\left.\mathrm{Cp}^{*} \mathrm{Ni}\right)$, and the isoelectronic $\mathrm{Cp}_{2} \mathrm{Co}^{-}$, are known to undergo exoprotonation. ${ }^{12,13,39}$ Here we find that, consistent with the near isoenergetic energies predicted by $\mathrm{DFT}, \mathrm{Cp}{ }_{2} \mathrm{Co}$ undergoes both exo- and endo-protonation on the ring. This result provides a distinct example of a metallocene that undergoes nonspecific protonation. Furthermore, the protonation selectivity can be altered by changing the steric profile of the acid.

We suspect that formation of the exo-isomer is likely critical to observing productive PCET reactions in $\mathrm{N}_{2} \mathrm{RR}$ mediated by the $\mathrm{P}_{3}{ }^{\mathrm{B}} \mathrm{Fe}$-system, as this isomer provides significantly less steric shielding for the reactive $\mathrm{H} \bullet$. Given the steric profile of the catalytically relevant acids that we and others have used (e.g., anilinium and pyridinium), ${ }^{4,5,6,7,8,9}$ we expect that exoprotonation is far more likely under $\mathrm{N}_{2} \mathrm{RR}$ conditions. Indeed, we have calculated only small barriers $\left(\Delta \mathrm{G}^{\ddagger}<5 \mathrm{kcal} \mathrm{mol}^{-1}\right)$ for the exo-protonation of $\mathrm{Cp}^{*}{ }_{2} \mathrm{Co}$ by substituted anilinium triflate acids. ${ }^{9}$ Facile endo-protonation by these acids is inconsistent with simple space-filling models. 
Although $\mathrm{Cp}^{*}$ is most typically considered to be an innocent ligand, evidence continues to emerge that it can be involved in the management of protons. In addition to the well-established protonation of $\mathrm{Cp}^{*}{ }_{2} \mathrm{Ni},{ }^{13,40}$ several half-sandwich $\mathrm{Rh}$ complexes have recently been reported to form $\mathrm{Cp}^{*}-\mathrm{H}$ linkages following reductive elimination of a $\mathrm{Rh}-\mathrm{H} .{ }^{41,42,43}$ In these cases, the $\mathrm{Cp}^{*}-\mathrm{H}$ bond has been directly implicated in $\mathrm{H}^{-}$transfer, either to $\mathrm{H}^{+}$or to $\mathrm{NAD}^{+}$.

The present study illustrates that $\mathrm{Cp}^{*}-\mathrm{H}$ linkages are not limited to $\mathrm{H}^{-}$transfer pathways. Rather, the type of reactivity can be predicted by the tendency of the metal center to achieve a closed-shell, $18 \mathrm{e}^{-} \mathrm{d}^{6}$ configuration. Thus, the $\mathrm{d}^{7}$ Co center in $\mathrm{Cp}^{*}\left(\right.$ exo $\left.-\eta^{4}-\mathrm{C}_{5} \mathrm{Me}_{5} \mathrm{H}\right) \mathrm{Co}^{+}$should favor a one electron process $(\mathrm{H} \bullet$ transfer $)$, while the $\mathrm{d}^{8} \mathrm{Co}$ center in $\mathrm{Cp}^{*}\left(\right.$ exo $-\eta^{4}-$ $\left.\mathrm{C}_{5} \mathrm{Me}_{5} \mathrm{H}\right) \mathrm{Co}$ should favor a two electron process $\left(\mathrm{H}^{-}\right.$transfer), akin to those observed for the aforementioned $\mathrm{d}^{8} \mathrm{Rh}$ centers.

In this work, we have derived a BDFE for three different $\mathrm{C}-\mathrm{H}$ bonds relevant to decamethylcobaltocene $\left(\mathrm{Cp}^{*}\left(\right.\right.$ exo- $\eta^{4}-$ $\left.\mathrm{C}_{5} \mathrm{Me}_{5} H\right) \mathrm{Co}^{+}, \quad \mathrm{Cp} *\left(\right.$ exo- $\left.\eta^{4}-\mathrm{C}_{5} \mathrm{Me}_{5} H\right) \mathrm{Co}$, and $\mathrm{Cp}^{*}\left(\eta^{5}-\right.$ $\mathrm{C} 5 \mathrm{Me} 4 \mathrm{CH}_{2} H$ ) Co) (Figure 8). All of these bonds are weak, but that in $\mathrm{Cp}^{*}\left(\right.$ exo $\left.-\eta^{4}-\mathrm{C}_{5} \mathrm{Me}_{5} H\right) \mathrm{Co}^{+}$is significantly weaker than the other two. This can be readily explained in terms of the two primary factors affecting the stability of the starting and product complexes: aromaticity and electron count. In the case of $\mathrm{H}$-atom abstraction from $\mathrm{Cp}^{*}\left(\right.$ exo $\left.-\eta^{4}-\mathrm{C}_{5} \mathrm{Me}_{5} \mathrm{H}\right) \mathrm{Co}$ or from a methyl substituent in $\mathrm{Cp}^{*}{ }_{2} \mathrm{Co}$, these factors offset one another to provide a weak, but not an exceptionally weak, C-H BDFE. For $\mathrm{Cp}^{*}\left(\right.$ exo- $\left.\eta^{4}-\mathrm{C}_{5} \mathrm{Me}_{5} \mathrm{H}\right) \mathrm{Co}, \mathrm{H}$-atom abstraction aromatizes the $\mathrm{Cp}^{*}$ ring, offset by the formation of a $19 \mathrm{e}^{-}$center. On the other hand, in $\mathrm{Cp}^{*}{ }_{2} \mathrm{Co}, \mathrm{H}$-atom abstraction transforms the $19 \mathrm{e}^{-}$ center to an $18 \mathrm{e}^{-}$center, but the $\mathrm{Cp}^{*}$ ring is dearomatized. Only in the case of $\mathrm{Cp}^{*}\left(\right.$ exo- $\left.\eta^{4}-\mathrm{C}_{5} \mathrm{Me}_{5} \mathrm{H}\right) \mathrm{Co}^{+}$are both stabilizing factors driving formation of the product. $\mathrm{H}$-atom abstraction affords aromatic, $18 \mathrm{e}^{-} \mathrm{Cp}_{2}{ }_{2} \mathrm{Co}^{+}$, and correspondingly the $\mathrm{C}-\mathrm{H}$ bond is remarkably weak (BDFE $<29 \mathrm{kcal} \mathrm{mol}^{-1}$ ).

Reagents with such weak $\mathrm{X}-\mathrm{H}$ bonds have been sought due to their utility in organic synthesis for the stepwise reduction of unsaturated substrates, such as olefins, ketones, aldehydes, esters, and enamines via $\mathrm{H} \bullet$ transfer. ${ }^{44,45}$ Traditional strategies for developing such reagents have focused on reactive metal hydrides, for which the $\mathrm{M} \bullet$ product of an overall hydrogen atom transfer is stabilized by dimerization via $\mathrm{M}-\mathrm{M}$ bond formation, and/or the formation of bridging carbonyl products. ${ }^{46}$ Another strategy has involved the coordination of substrates that contain otherwise strong $\mathrm{X}-\mathrm{H}$ bonds to a highly reducing, but nonetheless oxophilic/azaphilic, metal centers, resulting in remarkable weakening of the $\mathrm{X}-\mathrm{H}$ bond. ${ }^{47}$ One system where this phenomenon has proven particularly effective for engendering synthetically useful PCET reactions is $\mathrm{SmI}_{2}-\mathrm{H}_{2} \mathrm{O}$, in which coordination of $\mathrm{H}_{2} \mathrm{O}$ to $\mathrm{Sm}^{\mathrm{II}}$ has been estimated to result in an $\mathrm{O}-\mathrm{H}$ bond weakening of almost 100 kcal mol ${ }^{-1} \cdot 48,49,50,51$

The present study presents the protonation of $\mathrm{Cp}^{*}{ }_{2} \mathrm{Co}$ to form $\mathrm{Cp} *\left(\eta^{5}-\mathrm{C}_{5} \mathrm{Me}_{5} \mathrm{H}\right) \mathrm{Co}^{+}$as a distinct and promising strategy for developing extremely strong PCET donors. In general, this strategy involves coupling a $\mathrm{d}^{7}$ (or $\mathrm{d}^{4}$ ) metal ion to a dearomatized arene ligand. Given the prevalence of sandwich and halfsandwich complexes in organometallic chemistry, it is likely that as yet unrecognized examples of such PCET reagents already exist, or are readily accessible.

$\mathrm{Cp} *\left(\right.$ exo- $\left.\eta^{4}-\mathrm{C}_{5} \mathrm{Me}_{5} \mathrm{H}\right) \mathrm{Ni}^{2+}$ provides one such example. Electrochemical oxidation of the stable $\mathrm{Cp} *\left(\right.$ exo $\left.-\eta^{4}-\mathrm{C}_{5} \mathrm{Me}_{5} \mathrm{H}\right) \mathrm{Ni}^{+}$to $\mathrm{Cp} *\left(\right.$ exo $\left.-\eta^{4}-\mathrm{C}_{5} \mathrm{Me}_{5} \mathrm{H}\right) \mathrm{Ni}^{2+}$ leads to rapid generation of

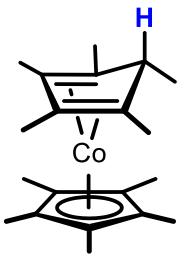

non-aromatic $18 e^{-}$

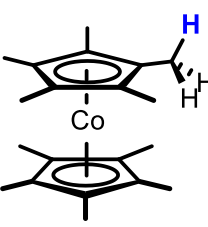

aromatic

$19 e^{-}$

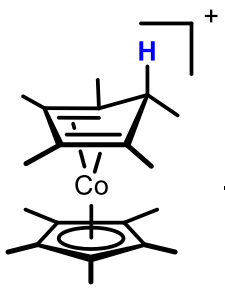

non-aromatic $17 e^{-}$

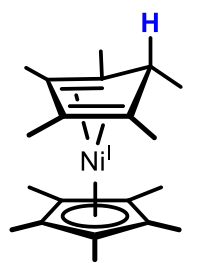

non-aromatic $19 e$

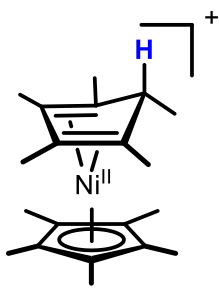

non-aromatic $18 e^{-}$

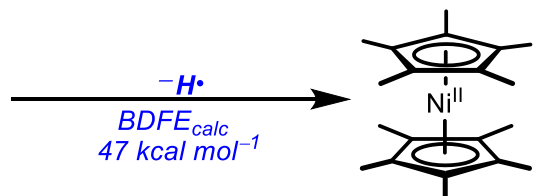
BDFE
$<29 \mathrm{kcal} \mathrm{mol}^{-1}$
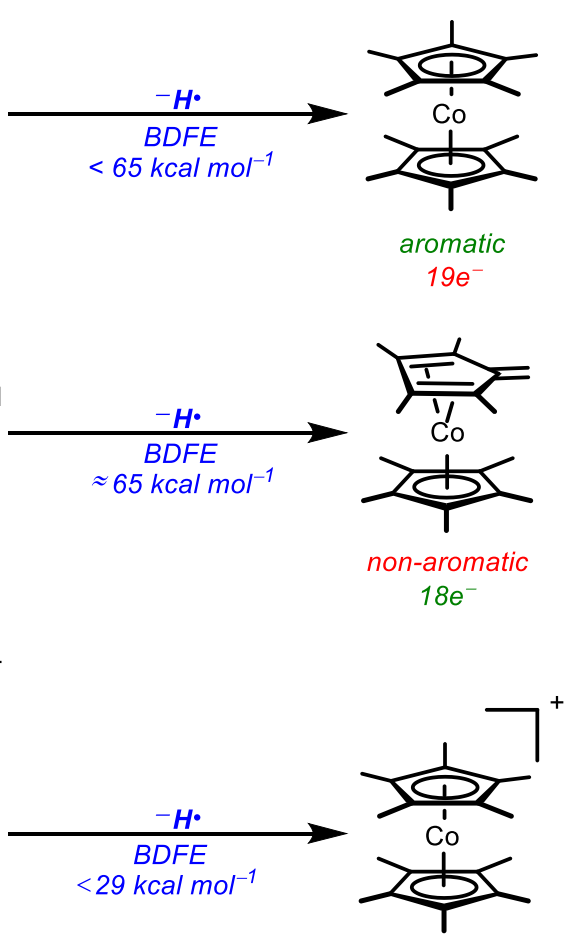

aromatic

$19 e$

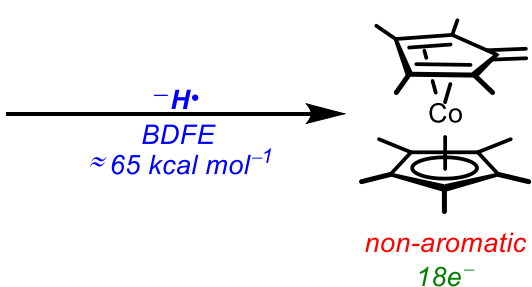

aromatic $18 e^{-}$

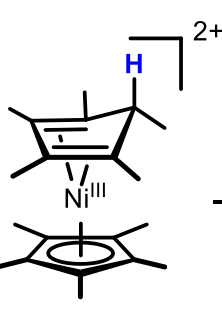

non-aromatic $17 e$

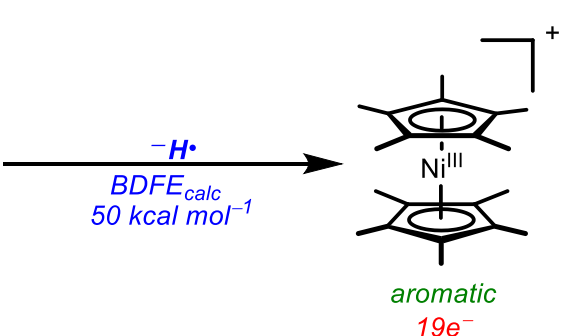

Figure 8: (top) A comparison of the experimental $\mathrm{BDFE}_{\mathrm{C}-\mathrm{H}}$ for a variety of related $\mathrm{Cp} * \mathrm{Co}$-species, demonstrating the importance of aromaticity and electron count in predicting the stability of the indicated $\mathrm{C}-\mathrm{H}$ bond. (bottom) A comparison of computational $\mathrm{BDFE}_{\mathrm{C}-\mathrm{H}}$ values for a redox series of $\left[\mathrm{Cp} *\left(\text { exo- }-\eta^{4}-\mathrm{C}_{5} \mathrm{Me}_{5} \mathrm{H}\right) \mathrm{Ni}\right]^{\mathrm{n}+}$. 
$\mathrm{Cp}_{2}{ }_{2} \mathrm{Ni}^{2+}$ on the $\mathrm{CV}$ time scale. This transformation was originally proposed to occur via $\mathrm{H}^{+}$loss followed by $\mathrm{e}^{-}$loss. ${ }^{52} \mathrm{Al}-$ ternatively, we suspect that, in analogy to $\mathrm{Cp}^{*}\left(\right.$ exo- $\eta^{4}$ $\mathrm{C}_{5} \mathrm{Me}_{5} \mathrm{H} \mathrm{Co}^{+}$, this transformation may occur via rapid $\mathrm{H} \cdot$ loss. In contrast, electrochemical reduction of the cation $\mathrm{Cp}^{*}$ (exo$\left.\eta^{4}-\mathrm{C}_{5} \mathrm{Me}_{5} \mathrm{H}\right) \mathrm{Ni}^{+}$to $\mathrm{Cp} *\left(e x o-\eta^{4}-\mathrm{C}_{5} \mathrm{Me}_{5} \mathrm{H}\right) \mathrm{Ni}$ is fully reversible on the $\mathrm{CV}$ time scale. ${ }^{52}$

These results emphasize that the electron count of the metal center, instead of its reducing power, can be a good predictor of the reactivity. Indeed, our DFT calculations and the relative experimental stability of $\mathrm{Cp} *\left(e x o-\eta^{4}-\mathrm{C}_{5} \mathrm{Me}_{5} \mathrm{H}\right) \mathrm{Ni}$ and $\mathrm{Cp} *\left(\right.$ exo- $\left.\eta^{4}-\mathrm{C}_{5} \mathrm{Me}_{5} \mathrm{H}\right) \mathrm{Ni}^{+}$suggest that even though $\mathrm{H} \cdot$ loss involves formal oxidation of the metal center the $\mathrm{d}^{9} \mathrm{Ni}^{\mathrm{I}}$ and $\mathrm{d}^{8}$ $\mathrm{Ni}^{\mathrm{II}}$ species are less prone to PCET reactivity. However, upon oxidation to the $\mathrm{d}^{7} \mathrm{Ni}^{\mathrm{III}}$ species the $\mathrm{C}-\mathrm{H}$ bond is weakened by approximately $20 \mathrm{kcal} \mathrm{mol}^{-1}$. This weakening is due to the high stability of the $18 \mathrm{e}^{-}, \mathrm{d}^{6} \mathrm{Cp}^{*}{ }_{2} \mathrm{Ni}^{2+}$ product resulting from net hydrogen atom transfer.

\section{CONCLUSION}

We have demonstrated using pulse EPR spectroscopy, supported by DFT calculations, that for $\mathrm{Cp}^{*}{ }_{2} \mathrm{Co}$ the $\mathrm{Cp} *$ ring is the site of protonation. Both ring-protonated isomers (endo and exo) can be formed and observed, with the selectivity being determined by the bulk of the acid. For the exo-species, we were able to use the one-electron reduced, neutral congener, $\mathrm{Cp} *\left(e x o-\eta^{4}-\mathrm{C}_{5} \mathrm{Me}_{5} \mathrm{H}\right) \mathrm{Co}$, to verify our DFT prediction that the protonated species, $\mathrm{Cp} *\left(\right.$ exo- $\left.\eta^{4}-\mathrm{C}_{5} \mathrm{Me}_{5} \mathrm{H}\right) \mathrm{Co}^{+}$, has a remarkably weak C-H bond $\left(<29 \mathrm{kcal} \mathrm{mol}^{-1}\right)$. This is consistent with the suggestion that it may serve as a PCET donor in catalytic $\mathrm{N}_{2} \mathrm{RR}$ in which it is generated in situ.

The facile protonation of $\mathrm{Cp}^{*}{ }_{2} \mathrm{Co}$ to generate $\mathrm{Cp} *\left(\right.$ exo- $\eta^{4}$ $\left.\mathrm{C}_{5} \mathrm{Me}_{5} \mathrm{H}\right) \mathrm{Co}^{+}$points to a more general strategy for developing conceptually related, strong PCET donors. Such strategies would complement current approaches for the development of PCET reagents, which rely on creating weak $\mathrm{M}-\mathrm{H}$ bonds or coordination-induced weakening of $\mathrm{O}-\mathrm{H}$ or $\mathrm{N}-\mathrm{H}$ bonds.

We have also shown that $\mathrm{Cp}^{*}\left(\right.$ exo- $\left.\eta^{4}-\mathrm{C}_{5} \mathrm{Me}_{5} \mathrm{H}\right) \mathrm{Co}^{+}$can be converted from a PCET donor to a strong hydride donor by one electron reduction, as demonstrated by the capacity of $\mathrm{Cp} *\left(\right.$ exo- $\left.\eta^{4}-\mathrm{C}_{5} \mathrm{Me} 5 \mathrm{H}\right) \mathrm{Co}$ to convert $\mathrm{CO}_{2}$ to formate. This observation highlights the dual potential for metallocenes to mediate both hydride transfer and PCET steps during the protoncoupled reduction of small molecule substrates (Figure 1). Both types of reactivity differ from the canonical role associated with metallocenes as electron transfer reagents.

\section{ASSOCIATED CONTENT}

\section{Supporting Information}

The Supporting Information is available free of charge on the ACS Publications website at DOI: $x x x x x x$.

Computational models (MOL)

X-ray data (CIF)

Experimental procedures and compound characterization data (PDF)

\section{AUTHOR INFORMATION}

\section{Corresponding Author}

*phoyala@caltech.edu

*jpeters@caltech.edu

\section{ORCID}

Paul H. Oyala: 0000-0002-8761-4667

Jonas C. Peters: 0000-0002-6610-4414

\section{Notes}

The authors declare no competing financial interest.

\section{Author Contributions}

The manuscript was written through contributions of all authors. All authors have given approval to the final version of the manuscript.

\section{ACKNOWLEDGMENTS}

This work was supported by Department of Energy (DOE0235032). MJC acknowledges support from the Center for Environmental Microbial Interactions (CEMI) and the Resnick Sustainability Institute at Caltech. The Caltech EPR facility was supported by the National Science Foundation (NSF MRI153194) and the Dow Next Generation Educator Fund.

\section{REFERENCES}

${ }^{1}$ Wilkinson, G.; Rosenblum, M.; Whiting, M. C.; Woodward, R. B. The structure of iron bis-cyclopentadienyl. J. Am. Chem. Soc. 1952, 74, 2125 2126.

${ }^{2}$ Ferrocenes; Štěpnička, P., Ed.; John Wiley and Sons, Ltd: Chichester, England, 2008; pp 641.

${ }^{3}$ Geiger, W. E. Organometallic electrochemistry: origins, development, and future. Organometallics 2007, 26, 5738-5765.

${ }^{4}$ Yandulov, D. V.; Schrock, R. R. Catalytic reduction of dinitrogen to ammonia at a single molybdenum center. Science 2003, 301, 76-78.

5 Arashiba, K.; Miyake, Y.; Nishibayashi, Y. A molybdenum complex bearing PNP-type pincer ligands leads to the catalytic reduction of dinitrogen into ammonia. Nat. Chem. 2010, 3, 120-125.

${ }^{6}$ Hill, P. J.; Doyle, L. R.; Crawford, A. D.; Myers, W. K.; Ashley, A. E. Selective catalytic reduction of $\mathrm{N}_{2}$ to $\mathrm{N}_{2} \mathrm{H}_{4}$ by a simple Fe complex. $J$. Am. Chem. Soc. 2016, 138, 13521-13524.

${ }^{7}$ Arashiba, K.; Eizawa, A.; Tanaka, H.; Nakajima, K.; Yoshizawa, K.; Nishibayashi, Y. Catalytic nitrogen fixation via direct cleavage of nitrogen-nitrogen triple bond of molecular dinitrogen under ambient reaction conditions. Bull. Chem. Soc. Jap. 2017, 90, 1111-1118.

${ }^{8}$ Chalkley, M. J.; Del Castillo, T. J.; Matson, B. D.; Roddy, J. P.; Peters, J. C. Catalytic $\mathrm{N}_{2}$-to- $\mathrm{NH}_{3}$ conversion by $\mathrm{Fe}$ at lower driving force: a proposed role for metallocene-mediated PCET. ACS Cent. Sci. 2017, 3, 217 223.

${ }^{9}$ Chalkley, M. J.; Del Castillo, T. J.; Matson, B. D.; Peters, J. C. Femediated nitrogen fixation with a metallocene mediator: exploring $\mathrm{p} K$ effects and demonstrating electrocatalysis. J. Am. Chem. Soc. 2018, 140, 6122-6129.

${ }^{10}$ Curphey, T. J.; Santer, J. O.; Rosenblum, M.; Richards, J. H. Protonation of metallocenes by strong acids. Structure of the cation. J. Am. Chem. Soc. 1960, 82, 5249-5250.

${ }^{11}$ Liles, D. C.; Shaver, A.; Singleton, E.; Wiege, M. B. New high yield syntheses of ruthenocene and osmocene and their decamethyl derivatives. The crystal structure of $\left[\mathrm{Ru}\left(\eta^{5}-\mathrm{C}_{5} \mathrm{Me}_{5}\right)_{2}\right]$. J. Organomet. Chem. 1985, 288 , c33-c36.

${ }^{12}$ Court, T. L.; Werner, H. Studies on the reactivity of metal $\pi$-complexes: $\mathrm{X}$. Concerning the mechanism of formation of the cationic triple decker sandwich complex $\left[\mathrm{Ni}_{2}\left(\mathrm{C}_{5} \mathrm{H}_{5}\right)_{3}\right]^{+}$, and the isolation of $\left[\mathrm{NiC}_{5} \mathrm{H}_{5}\right] \mathrm{BF}_{4} . J$. Organomet. Chem. 1974, 65, 245-251.

${ }^{13}$ Koelle, U.; Khouzami, F. Permethylated electron-excess metallocenes. Angew. Chem. Int. Ed. 1980, 19, 640-641.

${ }^{14}$ Koelle, U.; Infelta, P. P.; Graetzel, M. Kinetics and mechanism of the reduction of protons to hydrogen by cobaltocene. Inorg. Chem. 1988, 27, 879-883.

${ }^{15}$ Kuriyama, S.; Arashiba, K.; Nakajima, K.; Tanaka, H.; Kamaru, N.; Yoshizawa, K.; Nishibayashi, Y. Catalytic formation of ammonia from

Matthew J. Chalkley: 0000-0002-0484-7335 
molecular dinitrogen by use of dinitrogen-bridged dimolybdenumdinitrogen complexes bearing PNP-pincer Ligands: remarkable effect of substituent at PNP-pincer ligand. J. Am. Chem. Soc. 2014, 136, 97199731.

${ }^{16}$ Anderson, J. S.; Rittle, J.; Peters, J. C. Catalytic conversion of nitrogen to ammonia by an iron model complex. Nature 2013, 501, 84-87.

${ }^{17}$ Del Castillo, T. J.; Thompson, N. B.; Peters, J. C. A synthetic singlesite Fe nitrogenase: high turnover, freeze-quench ${ }^{57} \mathrm{Fe}$ Mössbauer data, and a hydride resting state. J. Am. Chem. Soc. 2016, 138, 5341-5350.

${ }^{18}$ Anderson, J. S.; Cutsail, G. E. III; Rittle, J.; Connor, B. A.; Gunderson, W. A.; Zhang, L.; Hoffman, B. M.; Peters, J. C. Characterization of an $\mathrm{Fe} \equiv \mathrm{N}-\mathrm{NH}_{2}$ intermediate relevant to catalytic $\mathrm{N}_{2}$ reduction to $\mathrm{NH}_{3} . J . A m$. Chem. Soc. 2015, 137, 7803-7809.

${ }^{19}$ Thompson, N. B.; Green, M. T.; Peters, J. C. Nitrogen fixation via a terminal Fe(IV) nitride. J. Am. Chem. Soc. 2017, 139, 15312-15315.

${ }^{20}$ Yandulov, D. V.; Schrock, R. R. Studies relevant to catalytic reduction of dinitrogen to ammonia by molybdenum triamidoamine complexes. Inorg. Chem. 2005, 44, 1103-1117.

${ }^{21}$ Wickramasinghe, L. A.; Schrock, R. R.; Tsay, C.; Müller, P. Molybdenum complexes that contain a calix[6]azacryptand ligand as catalysts for reduction of $\mathrm{N}_{2}$ to ammonia. Inorg. Chem. 2018, 57, 15566-15574.

${ }^{22}$ Malischewski, M.; Seppelt, K.; Sutter, J.; Heinemann, F. W.; Dittrich, B.; Meyer, K. Protonation of ferrocene: a low-temperature X-ray diffraction study of $\left[\mathrm{Cp}_{2} \mathrm{FeH}\right]\left(\mathrm{PF}_{6}\right)$ reveals an iron-bound hydrido ligand. Angew. Chem. Int. Ed. 2017, 56, 13372-13376.

${ }^{23}$ Hyde, J. S.; Pasenkiewicz-Gierula, M.; Jesmanowicz, A.; Antholine, W. E. Pseudo field modulation in EPR spectroscopy. Appl. Magn. Reson. 1990, 1, 483-496.

${ }^{24}$ Wittke, J. P.; Dicke, R. H. Redetermination of the hyperfine splitting in the ground state of atomic hydrogen. Phys. Rev. 1956, 103, 620-631.

${ }^{25} \mathrm{Hu}$, Y.; Shaw, A. P.; Estes, D. P.; Norton, J. R. Transition-metal hydride radical cations. Chem. Rev. 2016, 116, 8427-8462.

${ }^{26}$ Brown, T. L. Cobalt-59 nuclear quadrupole resonance spectroscopy. Acc. Chem. Res. 1974, 7, 408-415.

${ }^{27}$ Different functionals (TPSS, TPSSH, BP86, B3LYP) were used for both the optimization and also the single point calculation to determine the hyperfine coupling. In all cases, similar $T$-tensors and the highly disparate magnitude of the $a_{\text {iso }}$ for the endo- and exo-functionalized species were observed (See SI for full details).

${ }^{28}$ Harmer, J.; Finazzo, C.; Piskorski, R.; Ebner, S.; Duin, E. C.; Goenrich, M.; Thauer, R. K.; Reiher, M.; Schweiger, A.; Hinderberger, D.; Jaun, B. A nickel hydride complex in the active site of methyl-coenzyme $\mathrm{M}$ reductase: implications for the catalytic cycle. J. Am. Chem. Soc. 2008, 130, 10907-10920.

${ }^{29}$ Kinney, R. A.; Saouma, C. T.; Peters, J. C.; Hoffman, B. M. Modeling the signatures of hydrides in metalloenzymes: ENDOR analysis of a diiron $\mathrm{Fe}(\mu-\mathrm{NH})(\mu-\mathrm{H}) \mathrm{Fe}$ Core. J. Am. Chem. Soc. 2012, 134, 12637-12647.

${ }^{30}$ Green, M. L. H.; Pratt, L.; Wilkinson, G. 760. A new type of transition metal-cyclopentadiene compound. J. Chem. Soc. 1959, 3753-3767.

${ }^{31}$ Potentials in butyronitrile have been shown to be very good estimates of those in acetonitrile. Butyronitrile also enables low temperature electrochemistry to be performed, which is beneficial for this study: Izutsu, K. Reference electrodes for use in nonaqueous solutions In Handbook of Reference Electrodes; Inzelt, G., Lewenstam, A., Scholz, F., Eds.; Springer Berlin Heidelberg: Berlin, Heidelberg, 2013, p 145-187.

${ }^{32}$ Koelle, U. Electrochemistry of transition metal $\pi$-complexes. IV. Oxidation of cyclopentadienyl diolefine and cyclobutadiene cobalt complexes. Inorg. Chim. Acta 1981, 47, 13-18.

${ }^{33}$ Wiedner, E. S.; Chambers, M. B.; Pitman, C. L.; Bullock, R. M.; Miller, A. J. M.; Appel, A. M. Thermodynamic hydricity of transition metal hydrides. Chem. Rev. 2016, 116, 8655-8692.

${ }^{34}$ Ilic, S.; Alherz, A.; Musgrave, C. B.; Glusac, K. D. Thermodynamic and kinetic hydricities of metal-free hydrides. Chem. Soc. Rev. 2018, 47, 28092836.

${ }^{35}$ Ohki, Y.; Murata, A.; Imada, M.; Tatsumi, K. C-H bond activation of decamethylcobaltocene mediated by a nitrogenase $\mathrm{Fe}_{8} \mathrm{~S}_{7}$ P-cluster model. Inorg. Chem. 2009, 48, 4271-4273.
${ }^{36}$ Gas-phase BDFE values are consistently lower than those of solution species. However, complications arising from differential hydrogen bonding behavior precludes simple application of a correction factor that would better correlate the gas phase DFT-predicted value with the solution phase values inferred from experimental data.

${ }^{37}$ Bühl, M.; Grigoleit, S. Molecular dynamics of neutral and protonated ferrocene. Organometallics 2005, 24, 1516-1527.

${ }^{38}$ Sharma, N.; Ajay, J. K.; Venkatasubbaiah, K.; Lourderaj, U. Mechanisms and dynamics of protonation and lithiation of ferrocene. Phys. Chem. Chem. Phys. 2015, 17, 22204-22209.

${ }^{39}$ Geiger, W. E.; Bowden, W. L.; El Murr, N. An electrochemical study of the protonation site of the cobaltocene anion and of cyclopentadienylcobalt(I) dicarbollides. Inorg. Chem. 1979, 18, 2358-2361.

${ }^{40}$ Werner, H.; Dernberger, T. Untersuchungen zur Reaktivität von Metall$\pi$-Komplexen: XXXIII. Synthese und Reaktivität von Decamethyl- und Pentamethylnickellocen. J. Organomet. Chem. 1980, 198, 97-103.

${ }^{41}$ Pitman, C. L.; Finster, O. N. L.; Miller, A. J. M. Cyclopentadienemediated hydride transfer from rhodium complexes. Chem. Commun. 2016, 52, 9105-9108.

${ }^{42}$ Quintana, L. M. A.; Johnson, S. I.; Corona, S. L.; Villatoro, W.; Goddard, W. A.; Takase, M. K.; VanderVelde, D. G.; Winkler, J. R.; Gray, H. B.; Blakemore, J. D. Proton-hydride tautomerism in hydrogen evolution catalysis. Proc. Natl. Acad. Sci. U. S. A. 2016, 113, 6409-6414.

${ }^{43}$ Johnson, S. I.; Gray, H. B.; Blakemore, J. D.; Goddard, W. A. Role of ligand protonation in dihydrogen evolution from a pentamethylcyclopentadienyl rhodium catalyst. Inorg. Chem. 2017, 56, 11375-11386.

${ }^{44}$ Crossley, S. W. M.; Obradors, C.; Martinez, R. M.; Shenvi, R. A. Mn-, $\mathrm{Fe}-$, and Co-catalyzed radical hydrofunctionalizations of olefins. Chem. Rev. 2016, 116, 8912-9000.

${ }^{45}$ Gentry, E. C.; Knowles, R. R. Synthetic applications of proton-coupled electron transfer. Acc. Chem. Res. 2016, 49, 1546-1556.

${ }^{46}$ Hartung, J.; Norton, J. R. Catalysis involving the $\mathrm{H} \bullet$ transfer reactions of first-row transition metals. In Catalysis without Precious Metals; Bullock, R. M., Ed.; Wiley: 2010, p 1-21.

${ }^{47}$ Cuerva, J. M.; Campaña, A. G.; Justicia, J.; Rosales, A.; Oller-López, J. L.; Robles, R.; Cárdenas, D. J.; Buñuel, E.; Oltra, J. E. Water: the ideal hydrogen-atom source in free-radical chemistry mediated by $\mathrm{Ti}^{\mathrm{III}}$ and other single-electron-transfer metals? Angew. Chem. Int. Ed. 2006, 45, 5522-5526.

${ }^{48}$ Chciuk, T. V.; Flowers, R. A. Proton-coupled electron transfer in the reduction of arenes by $\mathrm{SmI}_{2}$-water complexes. J. Am. Chem. Soc. 2015, 137, 11526-11531.

${ }^{49}$ Chciuk, T. V.; Anderson, W. R.; Flowers, R. A. Proton-coupled electron transfer in the reduction of carbonyls by samarium diiodide-water complexes. J. Am. Chem. Soc. 2016, 138, 8738-8741.

${ }^{50}$ Chciuk, T. V.; Anderson, W. R.; Flowers, R. A. Interplay between substrate and proton donor coordination in reductions of carbonyls by $\mathrm{SmI}_{2}$-water through proton-coupled electron-transfer. J. Am. Chem. Soc. 2018, 140, 15342-15352.

${ }^{51}$ Kolmar, S. S.; Mayer, J. M. $\mathrm{SmI}_{2}\left(\mathrm{H}_{2} \mathrm{O}\right)_{\mathrm{n}}$ reduction of electron rich enamines by proton-coupled electron transfer. J. Am. Chem. Soc. 2017, 139, 10687-10692.

52 Koelle, U.; Khouzami, F.; Lueken, H. Permethylmetallocenes, III. Decamethylnickelocene: the neutral sandwich complex, the monocation, the dication, and their addition reactions. Chem. Ber. 1982, 115, 11781196. 
TOC Graphic:

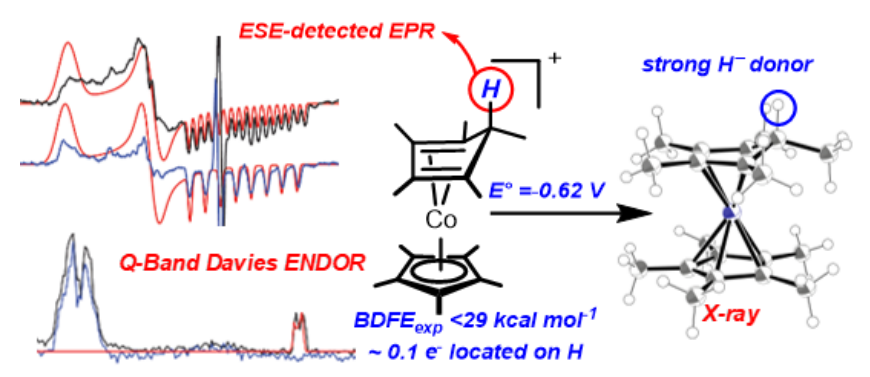

